University of Wisconsin Milwaukee

UWM Digital Commons

Theses and Dissertations

December 2014

\title{
Providing Alternative Reinforcers to Facilitate Tolerance to Delayed Reinforcement Following Functional Communication Training
}

Jillian Emily Austin

University of Wisconsin-Milwaukee

Follow this and additional works at: https://dc.uwm.edu/etd

Part of the Psychology Commons

\section{Recommended Citation}

Austin, Jillian Emily, "Providing Alternative Reinforcers to Facilitate Tolerance to Delayed Reinforcement Following Functional Communication Training" (2014). Theses and Dissertations. 660.

https://dc.uwm.edu/etd/660

This Thesis is brought to you for free and open access by UWM Digital Commons. It has been accepted for inclusion in Theses and Dissertations by an authorized administrator of UWM Digital Commons. For more information, please contact open-access@uwm.edu. 
PROVIDING ALTERNATIVE REINFORCERS TO FACILITATE TOLERANCE TO DELAYED REINFORCEMENT FOLLOWING FUNCTIONAL COMMUNICATION

\author{
TRAINING \\ by \\ Jillian E. Austin \\ A Thesis Submitted in \\ Partial Fulfillment of the \\ Requirements for the Degree of \\ Master of Science \\ in Psychology \\ at
}

The University of Wisconsin-Milwaukee

December 2014 


\section{ABSTRACT \\ PROVIDING ALTERNATIVE REINFORCERS TO FACILITATE TOLERANCE TO DELAYED R EINFORCEMENT FOLLOWING FUNCTIONAL COMMUNICATION TRAINING}

by

Jillian Austin

The University of Wisconsin-Milwaukee, 2014

Under the Supervision of Jeffrey H. Tiger

Functional communication training (FCT) is one of the most thoroughly researched treatments for severe problem behavior exhibited by individuals with intellectual and developmental disabilities. The earliest stages of FCT involve providing immediate and continuous reinforcement for a communicative response (FCR) that is functionally equivalent to the targeted problem behavior. However, maintaining immediate reinforcement is not practical, and the introduction of delays is associated with increased problem behavior. The present study evaluated the effects of providing alternative reinforcers during delays to reinforcement. Results indicated problem behavior was less likely when alternative reinforcers were available during delays.

Keywords: alternative reinforcers, delay fading, delay tolerance, extinction, functional communication training, noncontingent reinforcement, problem behavior 
(C) Copyright by Jillian Austin, 2014 All Rights Reserved 


\section{TABLE OF CONTENTS}

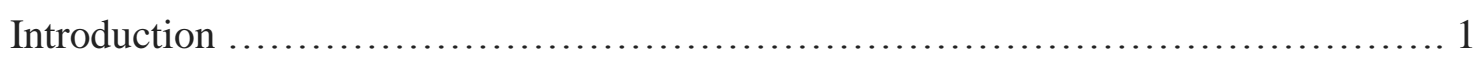

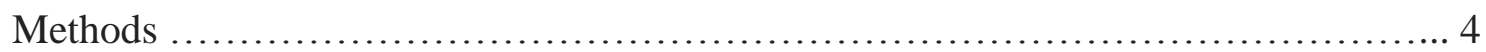

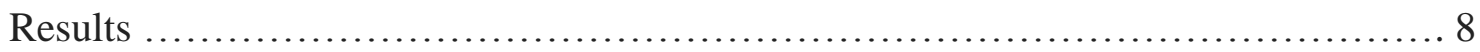

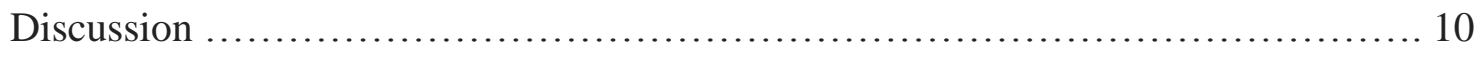

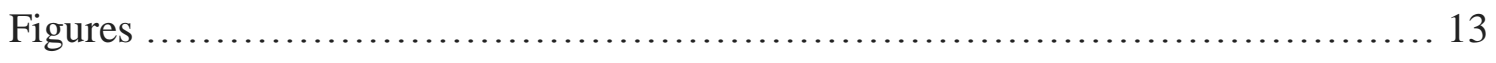

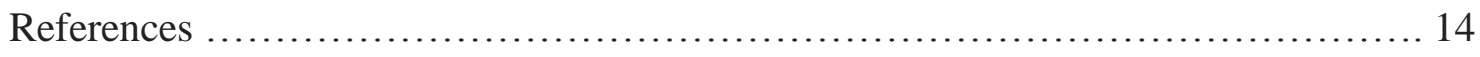




\section{LIST OF FIGURES}

Figure 1: Aggression and Functional Communicative Responses per min ................... 13 
Providing Alternative Reinforcers to Facilitate Tolerance to Delayed Reinforcement Following Functional Communication Training

Functional communication training (FCT; Carr \& Durand, 1985) is the most thoroughly researched function-based treatment for severe behavior disorders exhibited by individuals with intellectual and developmental disabilities (Tiger, Hanley, \& Bruzek, 2008). FCT involves (a) conducting a functional analysis to determine the environmental reinforcers maintaining problem behavior and (b) teaching a functionally equivalent communicative response to obtain that reinforcer; we refer to this alternative functional communicative response as the FCR. For instance, Carr and Durand (1985) taught four individuals with developmental disabilities to request attention (for those with attentionmaintained problem behavior) or assistance with difficult tasks (for those with escape from demands-maintained problem behavior), which served as effective replacements for problem behavior including aggression, tantrums, and self-injury.

Between the publication of Carr and Durand in 1985 and the publication year 2006, FCT procedures were replicated in 204 individual data sets across 91 published studies (Tiger et al., 2008). Across each of these published data sets, FCT was initiated by reinforcing the FCR on an immediate and continuous reinforcement schedule (i.e., each response produced the reinforcer without delay). Although immediate and continuous reinforcement represents the appropriate starting point for an FCT intervention to ensure the acquisition of the FCR, caregivers are unlikely to maintain these contingencies in the natural environment. Practically, the delivery of reinforcement is likely to be delayed when caregivers must retrieve a requested reinforcer (e.g., when a requested toy is located in another room), must terminate an ongoing activity in order to 
deliver reinforcement (e.g., when a caregiver is speaking to another adult, he or she would likely have to politely excuse themselves before attending to a child's request for attention) or when completion of a non-preferred task cannot be delayed (e.g. when a child must put on their shoes so his or her parent can arrive for work on time). These natural delays between the FCR and reinforcement may weaken the newly taught FCR and cause a re-emergence of problem behavior (Fisher, Piazza, Cataldo, Harrell, Jefferson, \& Conner, 1993; Fisher et al., 1998; Fisher, Thompson, Hagopian, Bowman, \& Krug, 2000; Hagopian, Fisher, Sullivan, Acquisto, \& LeBlanc, 1998; Hagopian, Toole, Long, Bowman, \& Lieving, 2004; Hanley, Iwata \& Thompson, 2001; Volkert, Lerman, Call, \& Trosclair-Lasserre, 2009). Recognizing the unavoidability and detrimental effects of delays to reinforcement in natural environments, it is imperative that research identify strategies to promote maintenance of the FCR and reduce problem behavior when reinforcement for the response is delayed.

Delay fading has been used in some cases to teach tolerance to delayed reinforcement following FCT. That is, after the FCR has been strengthened using immediate reinforcement, the therapist gradually introduces a delay between the FCR and the delivery of reinforcement. The delay begins brief (e.g., Hagopian et al., 1998 began with a 5-s delay) and is gradually extended until the terminal criterion (e.g., Hagopian et al., 1998 used a 5-min terminal criterion) is met. Hagopian et al. implemented delay fading following FCT for 12 participants receiving treatment for severe destructive behavior. The FCR maintained during fading with low levels of problem behavior in only five of these 12 applications. Although there have been a few published successes with delay fading following FCT, there have also been a number of published treatment 
failures in which the FCR was not maintained and problem behavior resumed once delays were extended (e.g., Fisher et al., 1993; Fisher et al., 2000; Hanley et al., 2001). Thus, delay fading alone has questionable efficacy in teaching tolerance to delayed reinforcement.

The efficacy of delay fading may be enhanced by providing a discriminative stimulus to signal the onset of a delay period (e.g., Fisher et al., 1998). For example, Vollmer, Borrero, Lalli, and Daniel (1999) compared an unsignaled-delay condition, in which the therapist stood still for $10 \mathrm{~s}$ after the child's mand prior to delivering chips, to a signaled-delay condition, in which the therapist placed his or her hand in a chip bag for the 10-s delay following the mand. One participant tolerated delays up to $10 \mathrm{~min}$ in the signaled condition relative to $10 \mathrm{~s}$ in the unsignaled condition.

Hagopian, Contrucci, Long, and Rush (2005) found that delay fading may also be enhanced by providing access to competing stimuli during delay periods. Three children with problem behavior maintained by attention or access to tangible items (social positive reinforcement) participated. The authors conducted a competing-stimulus assessment (Fisher, Piazza, Bowman, \& Amari, 1996) to identify stimuli that resulted in high levels of item engagement and low levels of problem behavior. Next, the experimenters taught participants to request access to the maintaining reinforcer (e.g., attention or video game) without delays to reinforcement and subsequently implemented delay fading. Problem behavior re-emerged during fading, so the authors provided competing stimuli during delays. Delay fading with competing stimuli was more effective (less problem behavior and delay fading proceeding more quickly) than delay fading without competing items. 
The current study served as a systematic replication and extension of Hagopian et al. (2005) by evaluating the effects of providing alternative reinforcers during delay periods following FCT. This evaluation was conducted with a single participant presenting with aggression maintained by two sources of social positive reinforcement.

\section{Methods}

\section{Subject and Setting}

Cameron, a 13-year-old boy with intellectual disability, agenesis of the corpus callosum, and conduct disorder, participated in this study. He was referred for the treatment of aggressive behavior towards caregivers. Cameron required some assistance with daily-living activities (e.g., toileting, bathing, and dressing) due to physical impairments in his lower extremities. Cameron had strong expressive verbal skills and could communicate at near age-appropriate levels. He communicated conversationally with others, but at times would fail to articulate clearly. All sessions were conducted in Cameron's bedroom, which contained a small table, lamp, television, stand, and Xbox ${ }^{\mathrm{TM}}$ game system.

\section{Measurement and Interobserver Agreement}

We scored Cameron's aggression including hitting, kicking, scratching, throwing objects in another person's direction, pinching, hair pulling, banging into a person, with his body or with another object, and grabbing. We also measured the occurrence of two vocal FCRs, "Excuse me" and "May I please play Xbox". Due to the length of the phrase targeted for the $\mathrm{Xbox}^{\mathrm{TM}}$, observers coded a vocalization if it was a complete sentence requesting to play his Xbox ${ }^{\mathrm{TM}}$ and included the word "please" (e.g., "Can I please play Xbox?” or "May I play Xbox, please?” were both acceptable). An observer collected 
data on the number of aggressions and each FCR using a laptop computer; each dependent measure is reported as a response rate (responses per min).

To assess interobserver agreement, a second observer concurrently and independently collected data during $45 \%$ of sessions. We partitioned each 10 -min session into 60, 10-s intervals and compared the two observers' records on an interval-by-interval basis using the proportional agreement method. That is, intervals in exact agreement were given a score of 1 and intervals not in exact agreement received a score by dividing the smaller number of responses by the larger number of responses. The scores for all intervals were then summed, divided by the total number of intervals, and converted into a percentage. These calculations resulted in a mean agreement for aggression of $96.3 \%$ (range: $73.5 \%$ to $100 \%$ ) and for FCRs of $96.3 \%$ (range: $84.6 \%$ to $100 \%$ ).

\section{Procedure}

Functional Analysis. We conducted a functional analysis of aggression based upon Iwata et al. (1982/1994) including 10-min toy-play, attention, tangible, escape, and ignore sessions. During toy-play sessions, we provided free and continuous access to an $\mathrm{Xbox}^{\mathrm{TM}}$ game system and the therapist provided noncontingent attention in the form of casual conversation. This condition served as the control condition. During attention sessions, the therapist withheld her attention and pretended to read a magazine. However, following problem behavior, the therapist presented a brief reprimand (e.g., "Ouch. Don't do that. That hurts me.”). During tangible sessions, the therapist provided access to the $\mathrm{Xbox}^{\mathrm{TM}}$ system for 1 to 2 min prior to session and then turned off the television set and retrieved the game-system remote control. Aggression resulted in the therapist returning the remote control and turning the television set on for $1 \mathrm{~min}$. During the escape 
sessions, the therapist prompted Cameron to engage in addition and subtraction problems. Each correct completion of a math problem resulted in brief praise whereas problem behavior resulted in the therapist removing the work for $30 \mathrm{~s}$. During ignore sessions, the therapist did not interact with Cameron and no materials were available.

Based upon the results of the functional analysis, we identified access to attention and tangible items as the maintaining sources of social positive reinforcement for Cameron's aggression. Therefore, we evaluated treatment for both sources of reinforcement in separate baselines (i.e., across an attention-delivery context and a tangible-delivery context) in a combination of reversal and concurrent multiple baseline designs. Sessions across contexts were randomized and counterbalanced.

Baseline (BL). As in the functional analysis, the therapist withheld reinforcement except following an instance of problem behavior. These baseline sessions were identical to the conditions of the functional analysis except that 30 -s access to the $\mathrm{Xbox}^{\mathrm{TM}}$ was provided in lieu of 1-min to provide additional response opportunities later in the treatment evaluation.

Noncontingent Reinforcement (NCR). In the NCR condition, Cameron received continuous access to the assessed reinforcer only. That is, during the NCR condition of the attention context, the therapist engaged in continuous casual conversation, but did not provide access to the $\mathrm{Xbox}^{\mathrm{TM}}$. During the NCR condition of the tangible context, the therapist provided free access to Cameron's Xbox ${ }^{\mathrm{TM}}$, but no attention was available. This phase confirmed that attention and tangible items served as two distinct forms of social positive reinforcement to which Cameron's aggression was sensitive. 
Functional Communication Training (FCT). The therapist taught Cameron to engage in the vocal FCR, "Excuse me" to recruit attention during attention sessions and to engage in the vocal response, "May I please play the Xbox?" during the tangible sessions. In both cases, the FCR resulted in $30 \mathrm{~s}$ of reinforcement and aggression was ignored. Prior to starting each FCT session, the therapist provided verbal discriminative stimuli to indicate which reinforcer was available in the upcoming session. Prior to the attention sessions, the researcher said, "When you want my attention, say, 'Excuse me." Before the tangible condition, the researcher said, "When you want to play Xbox, say 'May I please play the Xbox?'” Any requests for the non-targeted FCR were ignored (e.g., the therapist did not respond to the request, "Excuse me" during tangible sessions).

Terminal-Delay Probe. Prior to implementing delay fading, we assessed Cameron's tolerance to delayed reinforcement. These conditions were identical to the FCT condition except when Cameron emitted the correct FCR, the researcher said "In a minute" and initiated a 5-min delay during which no consequences were provided for either appropriate or inappropriate behavior. When the 5-min delay elapsed, the researcher said either "Okay, we can talk now" (attention condition) or "Okay, you can play now" (tangible condition) and provided access to the specified reinforcer for $30 \mathrm{~s}$.

Delay Fading (Attention Condition Only). The delay-fading condition was identical to the 5-min delay condition except the delay was reduced initially to $30 \mathrm{~s}$. We extended the delay by $10 \mathrm{~s}$ following every two consecutive sessions in which aggression was below 0.5 responses per min. When problem behavior was above 1 per min for four consecutive sessions the delay was decreased by $20 \mathrm{~s}$. 
Delay Fading with Alternative Reinforcers (Attention Condition Only). This condition was identical to the delay fading condition except when Cameron emitted the FCR, the researcher said "In a minute, but you may play Xbox" and provided continuous access to the video game system until the delay period elapsed. The same criteria for advancing or decreasing the delay interval as described in the delay fading condition were applied.

Terminal Delay with Alternative Reinforcers. This condition was identical to the 5-min delay probe, except when Cameron emitted the FCR the researcher said "In a minute" and offered access to an alternative reinforcer during delay intervals. The alternative reinforcer was access to attention during delays to the game system.

\section{Results}

Figure 1 displays aggression and FCR rates in both the attention (top panel) and tangible (bottom panel) contexts. During baseline in the attention context, aggression was elevated $(M=18.4$ responses per min [rpm]; range, 12.4 to $22.1 \mathrm{rpm})$. We then exposed Cameron to NCR sessions where we provided continuous, free access to attention.

During the NCR conditions aggression was eliminated $(M=0)$, confirming the results of the functional analysis and showing that attention successfully competed with opportunities to play the $\mathrm{Xbox}^{\mathrm{TM}}$. In a reversal to baseline, aggression increased $(M=$ $11.2 \mathrm{rpm}$; range, 0.9 to $19.1 \mathrm{rpm})$.

During FCT, Cameron acquired the attention FCR ("Excuse me") quickly $(M=$ 1.9; range, 0 to $2.3 \mathrm{rpm})$ and problem behavior decreased substantially $(M=0.2 \mathrm{rpm}$; range, 0 to $1.7 \mathrm{rpm}$ ). After observing stable levels of the FCR and aggression, we conducted a terminal-delay probe $(5 \mathrm{~min})$ during which the FCR decreased $(M=0.2 \mathrm{rpm}$; 
range, 0 to $0.6 \mathrm{rpm})$ and aggression increased $(M=3.3 \mathrm{rpm}$; range, 0.1 to $7.9 \mathrm{rpm})$. We returned to the FCT condition to re-strengthen the FCR $(M=1.9 \mathrm{rpm}$; range, 1.5 to 2.4 $\mathrm{rpm})$; aggression again decreased $(M=0.2 \mathrm{rpm}$; range, 0 to $2.2 \mathrm{rpm})$. We then implemented delay fading. Aggression remained low initially, but increased until the delay reached $120 \mathrm{~s}$, at which time aggression increased to baseline levels. Our fading criteria did not allow an increase of the delays beyond this point. We then provided an alternative source of reinforcement (the $\mathrm{Xbox}^{\mathrm{TM}}$ ) during the delays to compete with aggression. With this alternative reinforcer available during delays to attention, Cameron readily met the 5-min criterion, his FCRs remained stable $(M=0.3 \mathrm{rpm}$; range, 0.1 to 0.9 rpm), and aggression occurred at low levels $(M=0.2 \mathrm{rpm}$; range, 0 to $3.2 \mathrm{rpm})$.

Tangible sessions were conducted concurrently with attention sessions (shown in the bottom panel of Figure 1). During baseline sessions in the tangible context, we saw elevated levels of aggression $(M=1.9 \mathrm{rpm}$; range, 0.8 to $3.3 \mathrm{rpm})$. We then exposed Cameron to NCR sessions, in which aggression was eliminated $(M=0)$, and returned to baseline, in which aggression increased $(M=2.8 \mathrm{rpm}$; range, 0.3 to $8.0 \mathrm{rpm})$. We then implemented FCT; Cameron's FCRs remained stable $(M=2.4 \mathrm{rpm}$; range, 0 to $6.5 \mathrm{rpm})$ and aggression remained low $(M=0.4 \mathrm{rpm}$; range, 0 to $5.9 \mathrm{rpm})$. We conducted a 5 -min terminal-delay probe, during which the FCR decreased $(M=0.2 \mathrm{rpm}$; range, 0 to 0.3 $\mathrm{rpm})$ and aggression increased $(M=3.5 \mathrm{rpm}$; range, 1.2 to $4.8 \mathrm{rpm})$. We returned to the FCT condition and the FCR returned at high levels ( $M=2.4 \mathrm{rpm}$; range, 0.4 to $4.9 \mathrm{rpm})$ and aggression decreased $(M=.3 \mathrm{rpm}$; range, 0 to $3.6 \mathrm{rpm})$. We conducted an additional 5-min delay probe in which the FCR again decreased $(M=0.4 \mathrm{rpm}$; range, 0 to $0.8 \mathrm{rpm})$ and aggression increased $(M=3.7 \mathrm{rpm}$; range, 0 to $12.5 \mathrm{rpm})$. 
Finally, we implemented the terminal delay probe with access to the alternative reinforcer (i.e., attention) during delays to Cameron's Xbox ${ }^{\mathrm{TM}}$. With the alternative reinforcer available, Cameron engaged in the FCR at stable and efficient levels $(M=0.2$ rpm; range, 0 to 0.3$)$, and near zero levels of aggression $(M=0.2 \mathrm{rpm}$; range, 0 to 2.2) across roughly 30- sessions.

\section{Discussion}

The current study evaluated several procedures for teaching tolerance to delayed reinforcement following functional communication training with a boy presenting with severe aggressive behavior maintained by two sources of social positive reinforcement. Results indicated problem behavior was less likely when alternative reinforcers were available during delays to reinforcement.

There were several notable findings in this evaluation. First, the current study adds to the well-established literature on the use of FCT (Tiger et al., 2008) to successfully reduce problem behavior. When implemented without delays to reinforcement, FCT effectively reduced Cameron's aggression to zero levels in both the attention and tangible contexts. Second, the introduction of delays resulted in a rapid loss of treatment effects across both intervention contexts. These results highlight the detrimental effects of delays, similar to Fisher et al. $(1993 ; 2000)$ and Hanley et al. (2001).

Third, delay fading without alternative stimuli was largely ineffective, even when the onset of these delays was signaled. This result is different from those reported by Vollmer et al. (1999) and by Kelley, Lerman, Fisher, Roane, and Zangrillo (2011), who both reported successful delay fading when delay periods were signaled following FCT. 
There was one notable procedural difference between those studies, in which delays were signaled continuously (i.e., the signal was presented at the onset of the delay and removed only when reinforcement was delivered) and the current study, in which delays were signaled briefly (i.e., signals were presented and removed at the onset of the delay). Research has shown that continuous discriminative stimuli may be more effective at maintaining stimulus control, particularly over longer intervals (e.g., Schaal \& Branch, 1990; Tiger, Hanley, \& Larsen, 2008), but the effects of brief and continuous stimulus presentation have not yet been evaluated in the context of FCT. This remains an important area for future research.

Fourth, delay fading up to 5 min was effective only when an alternative source of reinforcement was available during delay intervals. These results are similar to those of Hagopian et al., (2005) and provide the first systematic replication of Hagopian et al. of which we are aware. It is notable that each participant in Hagopian et al. presented with problem behavior maintained by a single source of reinforcement (attention or tangible items), whereas Cameron presented with problem behavior maintained by multiple sources of reinforcement.

Fifth, this within-subject evaluation provided an opportunity to assess the generalization of tolerance to delayed reinforcement across contexts. That is, we conducted two terminal-delay probes in the tangible context, once prior to successful delay fading in the attention context and once following. In the absence of available alternative reinforcers, there was no generalization of "delay tolerance."

The current study also differed somewhat in the selection of alternative sources of reinforcement. Hagopian et al. used the competing-item preference assessment described 
by Piazza et al. (2006), which involved identifying functionally arbitrary reinforcers from caregiver nomination and evaluating them each singly to determine which stimuli provided sufficient competing reinforcement. In the current study, we selected alternative reinforcers that had been demonstrated to maintain aggression in the functional analysis and also evaluated them singly; the NCR phases were equivalent to the Piazza et al.'s competing-items assessment and demonstrated that both functional reinforcers successfully served as competing reinforcers.

The current study was also unique in that we assessed the effects of providing alternative reinforcers during delay intervals without delay fading (in the tangible context only). In this case, delay fading was not necessary. However, it is not clear if (a) fading would have also been unnecessary in the attention condition or (b) if the exposure to delay fading in the attention condition may have facilitated Cameron's tolerance to delayed reinforcement in the tangible condition. Future research should investigate these possibilities.

At the conclusion of this evaluation, Cameron's caregivers could delay the availability of both attention and access to his video game system. We believe that offering alternative reinforcers during delay intervals was a fairly practical solution to the challenges of implementing FCT in normative environments. However, researchers' beliefs should not serve as a proxy for the consumer's values of the behavioral interventions, namely the children and their caregivers. A direct assessment of caregivers implementing such interventions in more normative environments will provide important social validity data to verify the practicality of this approach. 


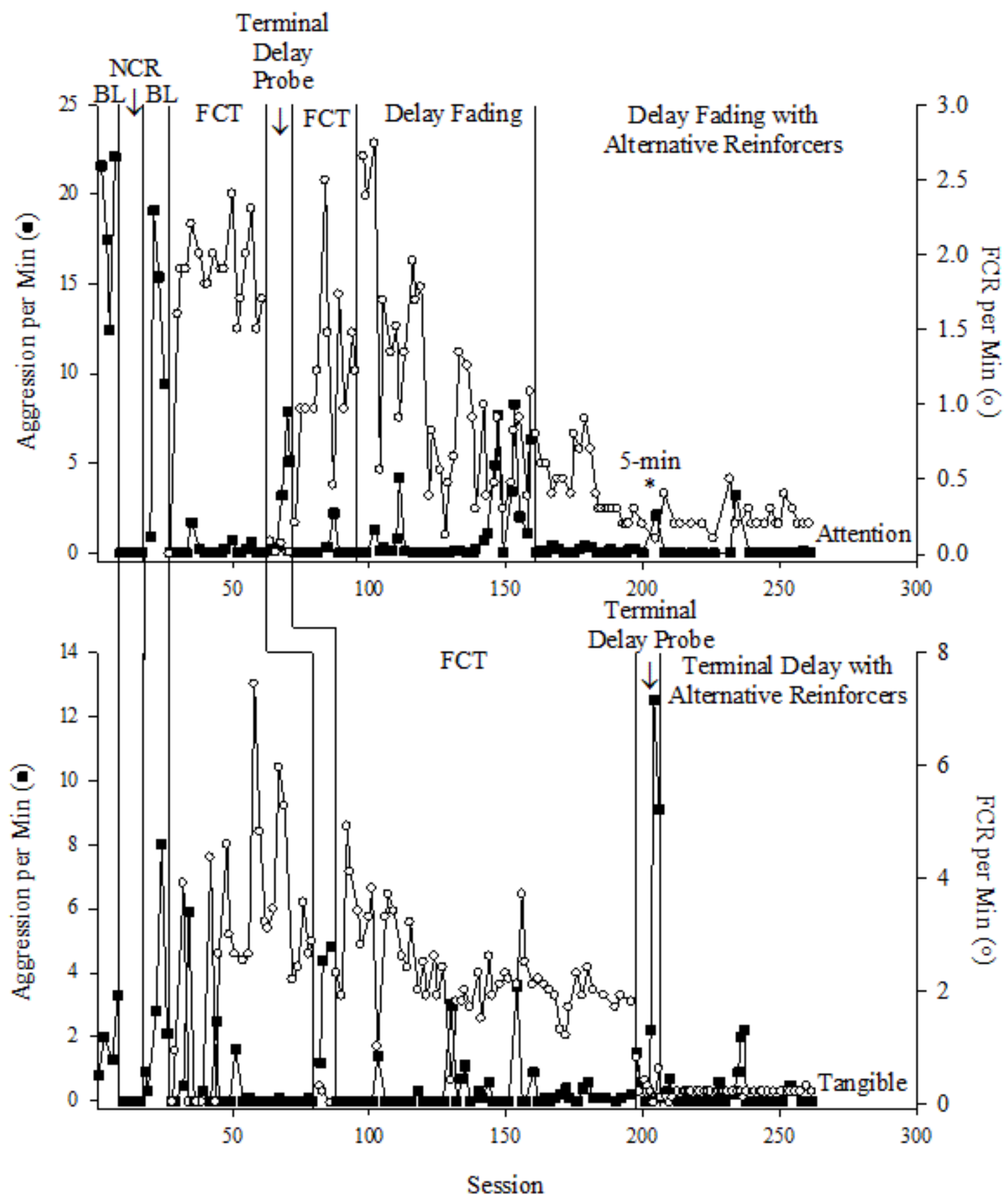

Figure 1. Aggression (left y-axis) and Functional Communicative Responses (FCR; right $y$-axis) per min across attention (top panel) and tangible (bottom panel) contexts. The asterisk (*) indicates when the 5-min delay criterion was met (i.e., fading was completed). 


\section{References}

Carr, E. G., \& Durand, V. M. (1985). Reducing behavior problems though functional communication training. Journal of Applied Behavior Analysis, 18, 111-126. doi: 10.1901/jaba.1985.18-111

Fisher, W. W., Kuhn, D. E., \& Thompson, R. H. (1998). Establishing discriminative control of responding using functional and alternative reinforcers during functional communication training. Journal of Applied Behavior Analysis, 31, 543-560. doi: 10.1901/jaba.1998.31-543

Fisher, W., Piazza, C., Cataldo, M., Harrell, R., Jefferson, G., \& Conner, R. (1993). Functional communication training with and without extinction and punishment. Journal of Applied Behavior Analysis, 26, 23-36. doi: 10.1901/jaba.1993.26-23

Fisher, W. W., Thompson, R. H., Hagopian, L. P., Bowman, L. G., \& Krug, A. (2000). Facilitating tolerance of delayed reinforcement during functional communication training. Behavior Modification, 24, 3-9. doi: 10.1177/0145445500241001

Hagopian, L. P., Contrucci, S. A., Long, E. S., \& Rush, K. S. (2005). Schedule thinning following communication: Using competing stimuli to enhance tolerance to decrements in reinforcer density. Journal of Applied Behavior Analysis, 38, 177193. doi: 10.1901/jaba.2005.43-04

Hagopian, L. P., Fisher, W. W., Sullivan, M. T., Acquisto, J., \& LeBlanc, L. A. (1998). Effectiveness of functional communication training with and without extinction and punishment: A summary of 21 inpatient cases. Journal of Applied Behavior Analysis, 31, 211-235. doi: 10.1901/jaba.1998.31-211 
Hagopian, L. P., Toole, L. M., Long, E. S., Bowman, L. G., \& Lieving, G. A. (2004). A comparison of dense-to-lean and fixed lean schedules of alternative reinforcement and extinction. Journal of Applied Behavior Analysis, 37, 323-337. doi:

10.1901/jaba.2004.37-323

Hanley, G. P., Iwata, B. A., \& Thompson, R. H. (2001). Reinforcement schedule thinning following treatment with functional communication training. Journal of Applied Behavior Analysis, 34, 17-38. doi: 10.1901/jaba.2001.34-17

Iwata, B. A., Dorsey, M., Slifer, K., Bauman, K., \& Richman, G. (1994). Toward a functional analysis of self-injury. Journal of Applied Behavior Analysis, 27, 197209. (Reprinted from Analysis and Intervention in Developmental Disabilities, 2, 3-20, 1982) doi: 10.1901/jaba.1994.27-197

Kelley, M. E., Lerman, D. C., Fisher, W. W., Roane, H. S., \& Zangrillo, A. N. (2011). Reinforcement delay fading during differential reinforcement of communication: The effects of signals on response maintenance. Journal of the Experimental Analysis of Behavior, 96(1), 107-122. doi: 10.1901/jeab.2011.96-107

Schaal, D. W., \& Branch, M. N. (1990). Responding of pigeons under variable-interval schedules of signaled- delayed reinforcement: Effects of delay-signal duration. Journal of the Experimental Analysis of Behavior, 53, 103-121. doi: 10.1901/jeab.1990.53-103

Tiger, J. H., Hanley G. P., \& Bruzek J. B. (2008). Functional communication training: A review and practical guide. Behavior Analysis in Practice, 1, 16-23. 
Tiger, J. H., Hanley, G. P., \& Larsen, K. M. (2008). A practical variation of a multipleschedule procedure: Brief schedule-correlated stimuli. Journal of Applied Behavior Analysis, 41, 125-130. doi: 10.1901/jaba.2008.41-125

Volkert, V. M., Lerman, D. C., Call, N. C., \& Trosclair-Lasserre, N. (2009). An evaluation of resurgence during treatment with functional communication training. Journal of Applied Behavior Analysis, 42, 145-160. doi:

10.1901/jaba.2009.42-145

Vollmer, T. R., Borrero, J. C., Lalli, J. S., \& Daniel, D. (1999). Evaluating self-control and impulsivity in children with severe behavior disorders. Journal of Applied Behavior Analysis, 32, 451-466. doi: 10.1901/jaba.1999.32-451 